\title{
Iranian Journal of
}

Educational

Sociology

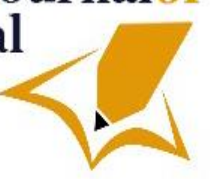

\section{Iranian journal of educational Sociology}

(Interdisciplinary Journal of Education)

Available online at: http://www.iase-idje.ir/

Volume 2, Number 2, July 2019

\section{Identifying the Dimensions and Components of Organizational Agility based on Human Resource Development to Provide a Model of Organizational Agility}

Fatemeh Soltani ${ }^{1}$, Fattah Nazem ${ }^{2 *}$, Mohammad Naghi Imani ${ }^{3}$

1. PhD student in Educational Management, Department of Educational Sciences, Roudehen Branch, Islamic Azad University, Roudehen, Iran.

2. Associate Professor, Department of Educational Sciences, Roudehen Branch, Islamic Azad University, Roudehen, Iran.

3. Assistant Professor, Department of Educational Sciences, Oral Branch, Islamic Azad University, Roudehen, Iran.

\section{Article history: \\ Received date: \\ Review date: \\ Accepted date:}

\begin{abstract}
Purpose: The purpose of this study was to identify the dimensions and components of organizational agility based on human resource development to provide a model of organizational agility in the Islamic Azad University of Tehran. Methodology: The present study was a mixed type (quantitative and qualitative) and at the same time it was an applied research. In this regard, the statistical population of the study includes all employees of the Islamic Azad University of Tehran in 2015- 17, which was about 6735, and using Morgan table and Cochran's formula and multi-stage cluster sampling method and relative 386 employees of the university as The sample size was considered. Data collection method was based on a researcher-made questionnaire, research literature and semi-structured interviews. And Cronbach's alpha coefficient of research tool was calculated 0.919. After distributing and collecting the questionnaires, reviewing the information and testing the hypotheses was done using structural equation modeling and SPSS, LISREL software.

Findings: Finally, the research findings confirmed the five dimensions, strategic, information technology, human, organizational and cultural, as dimensions affecting organizational agility based on human resource development. The results showed that the strategic dimension of the highest average and dimensions of information technology and human, organizational and cultural are in the next ranks. Finally, confirmatory factor analysis showed that the dimensions of organizational agility based on human resource development up to $71.282 \%$, the variance of existing indicators of organizational agility based on human resource development explains.

Conclusion: From the perspective of the studied sample, respectively, dimensions: strategic, information technology, human, organizational and cultural in the scale of measurement ( 1 to 4 ) have been important to a large extent and very much in organizational agility based on human resource development.
\end{abstract}

Please cite this article: Soltani F, Nazem F, Imani M N. (2019). Identifying the dimensions and components of organizational agility based on human resource development to provide a model of organizational agility in the Islamic Azad University of Tehran, Iranian journal of educational Sociology. 2(2):188- 197.

\footnotetext{
* Corresponding Author Email: F_Nazem@yahoo.com
} 


\section{Introduction}

In any country, the education system is one of the most complex social, economic and cultural subsystems; as always, a large number of people as learners and lecturers directly or indirectly deal with its activities. Universities, as one of the major centers of science, are of special importance; therefore, the main management of each country is the responsibility of its universities as a center of science production and training of experts. The role of each group in the field of higher education and the university, ie faculty members, students and staff, which form the three vertices of the higher education triangle, is important. University staff have a staffing, supportive and supportive role, and it must be acknowledged that in the near future university staff will no longer be able to play the role as in the past, because the two factors change the demands and expectations of customers (students and professors) on the one hand and changes Social and information technology, on the other hand, will change the role of universities and also change the definition of productivity and efficiency of the university system. Therefore, attention to organizational agility with the major role of human resources and the importance of staff growth and promotion in the form of human resource agility in the university is more visible and should be given serious attention (Moghaddasi, et al, 2015).

Today, technological and technological changes, information and education, globalization and instability, diversity of needs and expectations of learners, faster change, the need for universities to respond, their social and moral responsibility to society, etc. have created conditions that methods and Traditional paradigms of universities, as in the past, are no longer able to adequately respond to the needs of their clients (Bagheri Karachi, Abbaspour, 2012). Studying the current situation in the Islamic Azad universities of our country, it is clear that the successful efforts of their officials to identify change and create effective challenges in this area and take advantage of these changes to improve and develop their human resources less. In other words, our educational system is a non-dynamic and one-axis system and has a traditional and quantitative structure (Sahami, 2012).

The question here is how organizations (especially universities and research centers) can achieve agility? A review of previous studies on organizational agility has shown how an organization can achieve and maintain agility advantage. Among the tools mentioned by the experts of these organizations for achieving agility are flexible structure, human resource development, technology, information technology, innovation and creativity. Despite the importance of each of these factors and tools to streamline the organization, researchers have emphasized that human resource development is one of the most important (Dyer and Schaefer, 2003).

The concept of agility in the dictionary means fast, agile, active and the ability to move quickly and easily, as well as the ability to think quickly and intelligently (Hornby, 2000). Agility means the ability of any organization to feel, perceive and anticipate changes in the business environment. Such an organization must be able to recognize environmental changes and view them as a factor in growth and prosperity (Sharifi and Zhang, 1999). The problem of how organizations can succeed in a dynamic and unpredictable environment is one of the most important challenges in today's world. In such an environment, agility has become an important capability that has many effects on the performance of the organization (Ravichandran, 2007). In this way, one of the most fundamental mistakes is ignoring the prominent role of human resources in promoting agility. Although manpower agility has been touted as a profitable strategy in the business environment, the lack of agile manpower has been identified as one of the main reasons for organizations' failure to keep pace with market and technology changes (Torng Lin, ET all, 2005).

Agile organizations try to enrich their product in order to increase the value received by customers from the product. This makes the position of agile organizations inaccessible to competitors (Crocitto and Youssef, 2003). The foundation of an agile organization is the alignment of information technologies, employees, work processes and facilities in a flexible organization and the existence of a rapid response to changing conditions will also complement these capabilities (Dyer and Schaefer, 2003). 
Agility can also be considered as the ability of an organization to balance compliance and commitment and maintain it. Agile organizations do not place themselves in difficult situations where the vision is aimless and focused on routine actions. According to Doz and Kosunen (2010), strategic agility is the result of three characteristics in the organization. The term transcendence has been used to describe these three attributes that have been carefully adapted to the concept of dynamism. These three meta-capabilities include strategic sensitivity, resource fluidity, and collective commitment. Dyer and Schaefer (2003) on the issue of achieving organizational agility by employees examined the behavioral factors for organizational manpower agility and concluded that organizational agility requires behavior change in organizational manpower. Sherehiy,et al (2007) consider a range of pervasive agility capabilities: 1) flexibility 2) responsiveness 3) culture of change 4) speed 5) high integration and low complexity.

Ambrose and Morilla (2004) consider agile organization design to be possible by balancing order and change in the business environment. They stated: formulating a strategy of sourcing, resource management, creating and strengthening competencies in employees, training and identifying leaders, a central process, setting up a structure based on information system and coherence in the field of readiness to change the requirements of an agile organization. Sumukadas and Sawhney (2014) presented a theoretical model according to which they showed the effect of human resource management measures on human resource agility. In fact, the effect of actions that lead to employee involvement (called IE for short) and increase their motivation and commitment; The results showed that organizational power sharing methods such as job enrichment and development, self-management teams, quality circles and suggestion systems have a strong and significant impact on human resource agility.

On the other hand, in traditional management texts, human resource development is a set of individual and organizational actions that aim to increase the potential share of individuals in the organization. In today's dynamic environment, knowledge-based organizations require organizations to develop their learning capacity more effectively and faster than competitors, and to find ways and skills to solve complex problems. Therefore, reliance on human and intellectual capital is a sustainable competitive advantage in a knowledgebased economy and requires the development of skills and empowerment of the organization's human resources (Zhu, 2004). Human Resource Development believes that organizations are man-made institutions that rely on human expertise that are formed to determine and achieve their goals, including the development of organizational, group, individual and work processes cohesion. Slow (Abtahi, 2004). Human resource development functions are different from human resource functions. RAO enumerates the following roles for the Director of Human Resource Development: 1) Development of empowerment capabilities in individuals and systems; 2) integration of individual development and organizational development; 3) Maximizing the learning opportunities of people in the organization through various mechanisms; 4) work independence and shared responsibility; 5) Balancing change and adaptation; Provide feedback and reinforcement mechanisms, etc (RAO, 2007).

Table1. Dimensions and components extracted from research literature and interviews

\begin{tabular}{cr}
\hline Dimensions & Components \\
\hline Strategic & Strategic vision \\
\hline Strategic & Policy and policymaking \\
\hline Strategic & Mission and values \\
\hline Strategic & Values \\
\hline human & Continuous training and staff development \\
\hline human & Innovation and creativity \\
\hline human & Professional ethics and responsibility \\
\hline human & Attitude to learning and self-actualization \\
\hline human & Knowledge sharing, transfer of experiences \\
\hline Cultural & Culture of change \\
\hline Cultural & Culture of flexibility \\
\hline
\end{tabular}




\begin{tabular}{cr}
\hline Cultural & Provide solutions to deal with problems related to change \\
\hline Organizational & Performance evaluation system \\
\hline Organizational & Corporate Communications \\
\hline Organizational & Employee participation \\
\hline Organizational & Improving job skills \\
\hline Technology & Existence of regular communication networks \\
\hline Technology & Upgrading technologies to develop knowledge and skills \\
\hline Technology & Ability to reshape technologies \\
\hline
\end{tabular}

This research seeks to answer the following questions: 1) what are the different components affecting organizational agility based on human resource development? 2) What are the different dimensions affecting organizational agility based on human resource development? 3) What is the model of organizational agility based on human resource development in the Islamic Azad University of Tehran? 4) What is the validity of the model presented in the Islamic Azad University of Tehran?

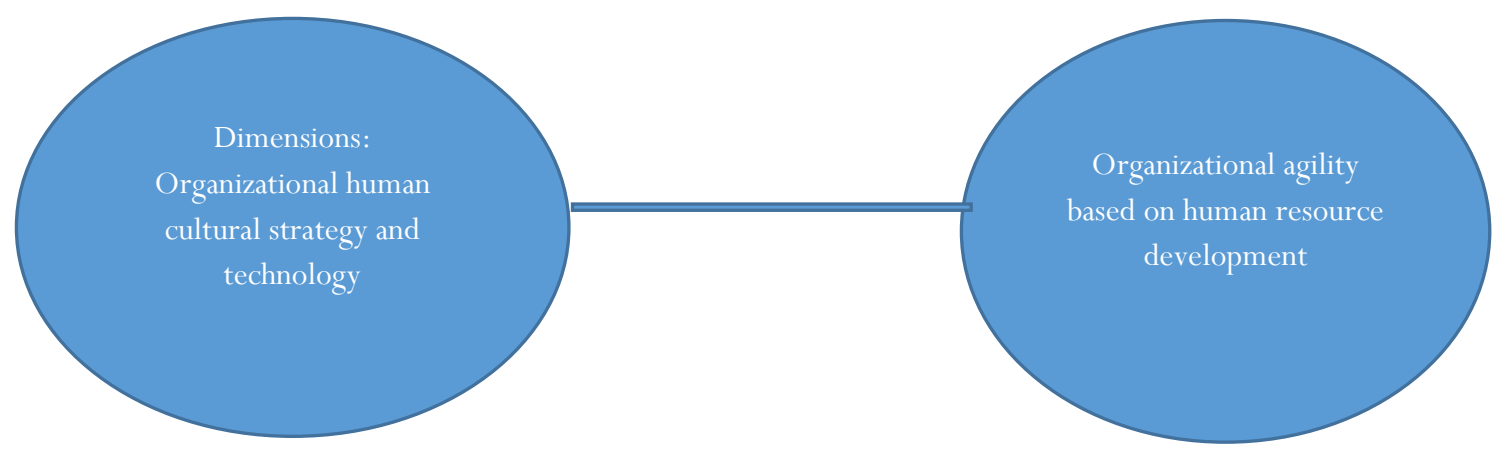

Figure1. Conceptual model of research

\section{Methodology}

The present study is of mixed type (quantitative and qualitative) and at the same time it is an applied research. In terms of environment, it is of the field type. This descriptive research is a survey type and descriptive statistics and inferential statistics have been used in different stages of the research. The statistical population of this research in a small part includes all the staff of the Islamic Azad University of Tehran in the years 2015-17; whose number was 6735 people. The sample size of 386 people was selected using Cochran's formula and Morganan table and was calculated by multi-stage and relative cluster sampling. In this study, a researcher-made questionnaire was used to collect data.

Table2. Demographic characteristics

\begin{tabular}{|c|c|c|}
\hline Demographic characteristics & Floor & Percentage \\
\hline \multirow{2}{*}{ Gender } & male & $\% 59 / 85$ \\
\hline & female & $\% 39 / 63$ \\
\hline \multirow{3}{*}{ Education rate } & Bachelor & $\% 9 / 3$ \\
\hline & MA & $\% 56 / 6$ \\
\hline & Doctorate & $\% 34 / 3$ \\
\hline \multirow{3}{*}{ Years of service } & years 6and 3Between & $\% 7$ \\
\hline & years 10and 7Between & $\% 16 / 01$ \\
\hline & years and up 11 & $\% 76 / 08$ \\
\hline \multirow{2}{*}{ education } & Related to management & $\% 50 / 1$ \\
\hline & Unrelated to management & $\% 49 / 9$ \\
\hline
\end{tabular}

The validity of the research questionnaire was confirmed using content validity method and with the opinion of supervisors and consultants, as well as several experts in the field of organizational agility and human resource development, after applying limited corrections. To assess the reliability of the 
instrument, a research questionnaire was distributed among 40 samples and was assessed by calculating Cronbach's Morrerd alpha. Cronbach's alpha was calculated to be 0.919 .

Table3. Cronbach alpha values of the questionary

\begin{tabular}{cccc}
\hline Next & The names of the items & Cronbach's alpha & Number of items \\
\hline Strategic & $18-1$ & $0 / 939$ & 18 \\
\hline Cultural & $32-19$ & $0 / 909$ & 14 \\
\hline human & $57-33$ & $0 / 896$ & 25 \\
\hline Organizational & $72-58$ & $0 / 948$ & 15 \\
\hline Information Technology & $84-73$ & $0 / 907$ & 12 \\
\hline
\end{tabular}

The questionnaire consisted of 84 items with a four-point Likert scale (very low 1, low 2, high 3, and very high 4). Due to the fact that in this study, the mean variance index extracted for all research variables is above 0.5 , so the convergent validity of the model constructs is confirmed. The results are announced as follows.

Table4. Status of 5 dimensions and components of research

\begin{tabular}{|c|c|c|c|c|c|}
\hline Dimensions and components & Items & Average & $\begin{array}{c}\text { The standard } \\
\text { deviation }\end{array}$ & Arrange the components & $\begin{array}{l}\text { Arrange the } \\
\text { dimensions }\end{array}$ \\
\hline Strategic vision & 4 & 3.31 & 0.51 & 1 & \\
\hline Policy-making & 7 & 3.17 & 0.56 & 4 & \\
\hline Mission & 4 & 3.18 & 0.70 & 3 & \\
\hline Values & 3 & 3.19 & 0.64 & 2 & \\
\hline Strategic & 18 & 3.21 & 0.52 & - & 1 \\
\hline Culture of change & 4 & 3.00 & 0.69 & 2 & \\
\hline Culture of flexibility & 4 & 3.03 & 0.86 & 1 & \\
\hline $\begin{array}{l}\text { Provide solutions to deal with } \\
\text { problems related to change }\end{array}$ & 6 & 2.95 & 0.84 & 3 & \\
\hline cultural & 14 & 2.99 & 0.76 & - & 5 \\
\hline Continuous education and learning & 6 & 3.15 & 0.68 & 2 & \\
\hline Innovation & 4 & 3.13 & 0.73 & 3 & \\
\hline Professional ethics and responsibility & 7 & 3.03 & 0.70 & 5 & \\
\hline $\begin{array}{l}\text { Attitude towards learning and self- } \\
\text { fulfillment }\end{array}$ & 4 & 3.15 & 0.73 & 1 & \\
\hline $\begin{array}{l}\text { Knowledge sharing, transfer of } \\
\text { experiences }\end{array}$ & 4 & 3.04 & 0.67 & 4 & \\
\hline Human & 25 & 3.10 & 0.63 & - & 3 \\
\hline Performance evaluation system & 5 & 3.11 & 0.75 & 1 & \\
\hline Organizational Communications & 4 & 3.07 & 0.71 & 2 & \\
\hline Employee participation & 3 & 3.01 & 0.72 & 4 & \\
\hline Improving job skills & 3 & 3.02 & 0.73 & 3 & \\
\hline Organizational & 15 & 3.06 & 0.65 & - & 4 \\
\hline Regular communication networks & 4 & 3.07 & 0.73 & 3 & \\
\hline $\begin{array}{l}\text { Upgrading technologies to develop } \\
\text { knowledge and skills }\end{array}$ & 5 & 3.18 & 0.70 & 1 & \\
\hline Ability to reshape technologies & 3 & 3.16 & 0.77 & 2 & \\
\hline Information Technology & 12 & 3.14 & 0.67 & & 2 \\
\hline $\begin{array}{c}\text { Organizational agility, general } \\
\text { situation }\end{array}$ & 84 & 3.10 & 0.53 & & \\
\hline
\end{tabular}




\section{Findings}

The results showed that the "strategic" dimension from the perspective of the study sample with an average of 3.21 and a variance of 0.2704 had the greatest impact on achieving organizational agility based on human resource development. The "information technology" dimension with an average of 3.14 and a variance of 0.4489 is the second most important and effective dimension. The "human" dimension with an average of 3.10 and a variance of 0.3969 is the third most important and effective dimension identified. The organizational dimension with an average of 3.06 and a variance of 0.4252 is the fourth effective dimension and the cultural dimension with a mean of 2.99 and a variance of 0.5776 has been identified as the fifth dimension.

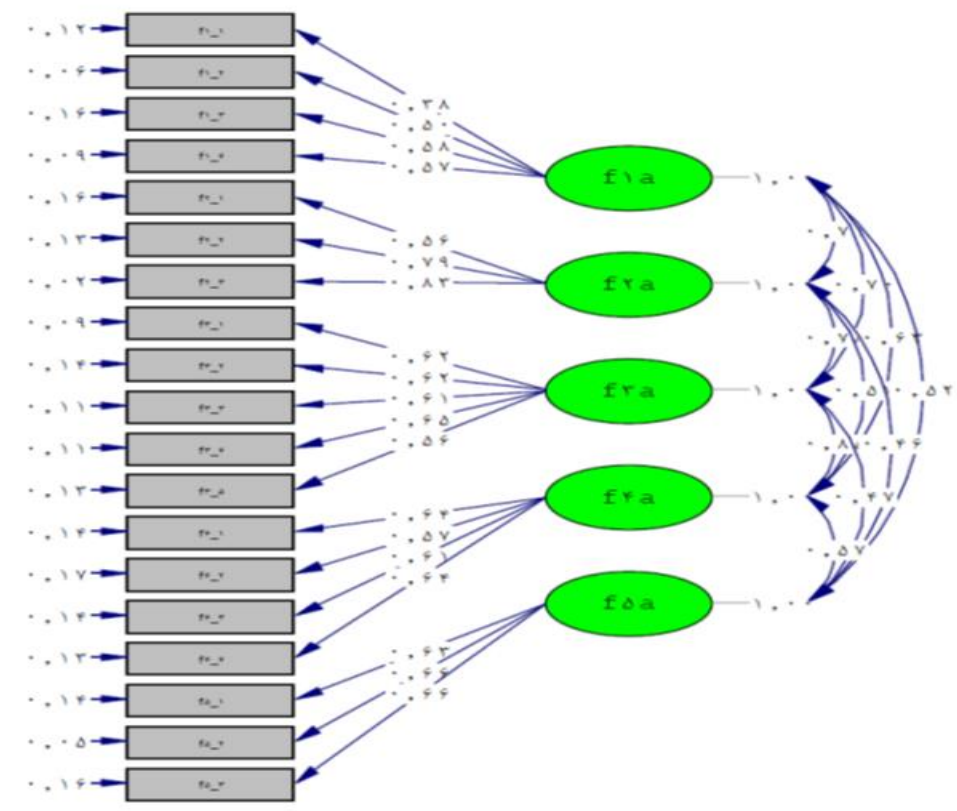

$0.079=$ R. M. S. A, $0.00000=\operatorname{Sig}, 142=$ Df, $483.33=\chi 2$

Figure2. ( 5 hidden dimensions and 19 explicit components)

Table5. ncealed and explicit dimensions and factor load

\begin{tabular}{|c|c|c|}
\hline Factor load & Obvious components & Concealed dimensions \\
\hline \multirow{5}{*}{$27 / 089$} & Professional creativity and responsibility & \multirow{5}{*}{ The human dimension } \\
\hline & Continuous learning training & \\
\hline & Knowledge sharing and information transfer & \\
\hline & Innovation & \\
\hline & Attitudes towards learning and self-actualization & \\
\hline \multirow{4}{*}{$17 / 019$} & Performance evaluation system & \multirow{4}{*}{ Organizational dimension } \\
\hline & Employee participation & \\
\hline & Corporate Communications & \\
\hline & Improving job skills & \\
\hline \multirow{3}{*}{$10 / 882$} & Regular communication networks & \multirow{3}{*}{ Information Technology } \\
\hline & Knowledge and information enhancement technologies & \\
\hline & Ability to reshape technologies & \\
\hline \multirow{4}{*}{$10 / 415$} & Strategic vision & \multirow{4}{*}{ Strategic dimension } \\
\hline & Policy and policymaking & \\
\hline & Mission & \\
\hline & Values & \\
\hline \multirow{2}{*}{$5 / 872$} & Culture of change & \multirow{2}{*}{ Cultural dimension } \\
\hline & Culture of flexibility & \\
\hline
\end{tabular}


Solutions to change-related problems

Figure 2 shows the measurement of organizational agility dimensions based on human resource development developed using LISREL software. The estimation results (bottom) indicate the suitability of the model. According to the laser output, the calculated chi-square value is equal to 483.33. The low value of this index indicates a slight difference between the conceptual model and the observed research data. Also, the value of RMSEA (root mean square of estimation errors) is equal to 0.079 and considering that the allowable limit of RMSEA is 0.09 , and this value is smaller than this allowable limit, it indicates a good fit.

Table6. Index range and good fit

\begin{tabular}{ccc}
\hline Fitness index & A good fit & Acceptable fit \\
\hline P-value & $\mathrm{P}<0.05$ & $\mathrm{P} 0.05 \leq P \leq 0.01$ \\
\hline$\chi^{2}$ & In a large sample size, it is always significant & \\
\hline$\chi^{2} / d f$ & $0 \leq \chi^{2} / d f \leq 2$ & $2 \leq \chi^{2} / d f \leq 3$ \\
\hline RMSEA & $0.050 \leq$ RMSEA $\leq$ & $0.05 \leq$ RMSEA $\leq 0.09$ \\
\hline
\end{tabular}

\section{Discussion}

Dimensions of the study sample: strategic, with an average of 3.21, information technology, with an average of 3.14, human, with an average of 3.10, organizational with an average of 3.06 and cultural, with an average of 2.99 and on a size scale Gaining ( 1 to 4 ) has been very important in organizational agility based on human resource development. Although the combination of the mentioned 5 dimensions showed the highest factor load in heuristic factor analysis (with an explanation of $71.28 \%$ variance), but the mentioned order changed in explaining organizational agility and in order of dimensions: human, with a factor load of 27.09, organizational, with a factor load of 02/0 17, Information technology, with a factor load of 10.88 , strategy with a factor load of 10.41 and culture with a factor load of 5.88 (71.28\% in total) are effective in organizational agility based on human resource development. The results of this research in human dimension are in line with the results of Hosseini, Rahnamai Rood Poshti and Niko (2009). He also stated in his findings that the spirit of participation, learning, and responsibility is important components in achieving organizational agility. In the strategic dimension, the results of the research are in line with their findings. According to him, the existence of a common vision (one of the important factors in the strategic dimension) is one of the important factors in achieving organizational agility and concludes that creating a common vision among employees it is one of the most sensitive steps in the transformation of the organization towards organizational agility. He also concluded that in the field of information technology in his research, the basis of agile organization is the alignment of information technologies, employees and work processes.

The results of this study are consistent with the research of Lane (2005). These results are also consistent with the results of Ghorbanizadeh, et al. (2011). In their research, they concluded that one of the five levers is to create agility in the information technology organization, and these results are in line with the results achieved by Gunasekaran (1999), Stewart, Brown (1996) and Sumukadas and Sawhney (2014). In this regard, (Bagheri Karachi, Abbaspour, 2012) stated in his research that an agile university to deal with environmental stimuli such as technological changes and transformations, constant changes in customer expectations and preferences, constant changes in students' expectations, the need for labor with It has high quality, innovative and learning. Universities need a series of enablers to realize agility capabilities, one of which is the agile organizational structure, which in the present study has been considered by university staff. These results are also consistent with Dyer and Schaefer (2003) research on organizational human resource agility. They stated that action-oriented initiative means seeking appropriate opportunities to participate in the success of the organization and play an active role in 
pursuing possible and promising opportunities. In the dimension of constructive behaviors, employees must simultaneously acquire and learn the necessary competencies and skills in several areas and improve their level of capability and culture by actively sharing knowledge and information. AL-Faouri AL-Nsour, AL-Kasabeh (2014) in a study entitled The Impact of Agile Workforce on Organizational Memory, according to three factors that Dyer and Schafer (2003) considered in their research, concluded that among the three factors Activism, adaptability and resilience, activism has had the greatest impact on organizational memory. The results of their research showed that the action-oriented workforce has a positive and significant effect on organizational guidelines and procedures and organizational memory, which in turn requires the presence of managers who promote activism and the action-oriented workforce by selection. Increase rain or other organizational interventions Morgan and Hunt (2007) research showed that the management of the organization to create an organization with efficient and capable manpower has no choice but to pay attention to training, strengthen creativity and initiative, raise morale and motivation, staff growth and the like. They stated that in order to achieve the goals of human resource development in the first stage, the performance of employees should be evaluated and evaluated in a desirable way (performance evaluation) and after identifying the strengths and weaknesses of employees in the above areas, to eliminate weaknesses and strengthen Strengths of action. These results are consistent with the findings of the present study. Khosravi and Abtahi research (2011) in line with the results of the present study showed that first the design and transformation of the organizational structure in a way in which it is possible to improve employees' attitudes toward their tasks and appropriate behavior is formed in them.

Such a structure can promote employee creativity and thus strengthen the processes of innovation and human resource development, and will also outline the strategic vision of the organization to move the organization towards human resource development and a better future. The results of Genoa and Hariri research also considered organizational culture as the second important factor in achieving human resource development in the organization that can provide appropriate interaction methods to achieve the desired level of human resource development. The results of research in the field of information technology are in line with the results of research by Khatami Hasnavi, et al (2013). In their research, they concluded that information technology has been identified as one of the most important enablers of organizational agility in Bahman Automotive Group. Also, these results are in line with the results obtained in Jazani and Rostami (2011). They concluded in their research that among the factors affecting the empowerment and development of human resources, the strategic factor plays the most important role. These results are in line with the findings of Amberius and Morella (2004). According to them, the strategy of sourcing and understanding the strategies of the organization are the general principles for creating an agile organization. Also, in the results of research by Crocitto and Yousef (2003) it is mentioned that strategic leadership can use the culture of the organization to achieve competitive advantage. Also, the management of the organization should be able to maintain the readiness of its employees in the face of different types of customers, the findings of Doz and Kosonen (2010) showed that strategic agility is the result of three characteristics in the organization. These characteristics include strategic sensitivity, resource fluidity, and collective commitment. In the study of Tseng and Lin (2010) who considered the mechanism, strategy and infrastructure as the basis of agility tools, it is also consistent with the results of the present study. Azar and Pishdar (2011) in their research used agility and supply chain measurement indicators related to Lin et al. (2005) and Sharifi and Zhang (1999) and focused on agility capabilities such as responsiveness, competence, flexibility and speed. They presented a model. They point to results such as the importance of a culture of flexibility in achieving organizational agility

If the Islamic Azad University of Tehran pays attention to the proposed model for achieving organizational agility based on human resource development, it will be able to move towards development goals and agility according to the evaluations and opinions of university staff and the priority of identified 
factors. Advance at the university. What has been observed so far in the Islamic Azad University of Tehran is a quantitative and mechanical improvement. As we know, the construction of new colleges and buildings includes the most changes, but attention to the developed and agile university in order to achieve the goals. And the prospects of the country should be given special attention by the planners of the Islamic Azad University of Tehran. 


\section{References}

Abtahi S H. (2004). . Training and Improving Human Capital (Vol. I). Tehran: Laniz Book Cultural Institute, Poyandeh Publications.

Agarwal A, Shankar R, Tiwari M.K. (2007), “Modeling agility of supply chain” Industrial Marketing Management Journal, 36(2007):443-457

AL-Faouri A , AL-Nsour M and AL-Kasabeh M M. (2014). "The impact of workforce agility on organizational memory, Knowledge Management Research \& Practice (12):432-442

Ambrose C, Morella, D (2004)," designing an agile organization”, available at: www.gartner.com/display document.

Amir Hosseini A, Rahnamai Rood Poshti Z,Niko M. (2009). "The role of human resources and its development in organizational agility" Fourth Conference on Human Resources Development

Azar A, Pishdar M. (2011). "Identification and measurement of organizational agility indicators, Journal of Management Research, 5(110; 5-20.

Bagheri Karachi A. Abbaspour A. (2012). Designing a favorable model for achieving organizational agility in universities", 69(48): 171-218.

Crocitto M, Youssef M, (2003), “The human side of organizational agility”2 International Journal of Industrial Management and Data systems, issn: 0263-5577

Doz Y. Kosonen M.(2010) “Embedding Strategic Agility A Leadership Agenda for Accelerating Business Model Renewal”. Long Range Planning. (43): 370-382.

Dyer L, Shafer R. (2003) "Dynamic organizations: achieving market place and3 organizational agility with people”, In: Peterson, R.S., Mannix, E.A. (Eds), Leading avd Managing people in the Dynamic organization. Laurence Erlbaum Associates, Mahwah, NJ., pp.71-77

Ghorbanizadeh V, et all. (2011). "The Role of Learning Culture and Knowledge Management in Organizational Agility" Quarterly Journal of Improvement and Transformation Management Studies, 24(5): 74- 84.

Gunasekaran A. (1999). "Agile Manufacturing: The Drivers, Concepts and Attributes," International Journal of Production Economics. 62(1): 33-43.

Hasnavi R, Nejatian M, Zanjirchi S M. (2013). "Analysis of Agility Paradigm for Specific Framework of Agile Manpower and Agile Organization" Journal of Management Improvement, 7(2): 77-98

Hornby A S. (2000). Oxford Advanced Learner's Dictionary of Current English, Sixth Edition, Oxford University press. 143

Jazani N, Rostami A. (2011). "Design and Development of Strategic Model of Human Resource Empowerment in KnowledgeBased Organizations" Journal of Human Resource Management Research, (3):23-54

Khosravi A, Abtahi S H. (2011). Identifying the Enabling Factors of Human Resource Agility by Delphi Method in Electronic Industries, Improving Management: 6(4): 129- 153.

Lin, C.T.; Chiu, H.; Chu, P.Y., (2006), “Agility index in the supply chain, International”, Journal of production Economics, 100, 285-299

Moghaddasi J, Mohammad Khani A, Davoodi M. (2015). Presenting a model for improving the staff of Islamic Azad University in Region 8 of the country.

Morgan R M, HuntS D. (2007). “The Commitment- Trust Theory of Relationship Marketing” 58(3): 71-79

Rao T V. (2007), "Is it time to replace HRD managers by knowledge and learning managers?" available at: http//indianmba.com/ Faculty Column /FC525/fc525.html (accessed 23 March 2007)

Ravichandran T. (2007). IT competencies, innovation capacity and organizational agility: Performance impact and the moderating effects of environmental characteristics. Lally School of Management \& Technology Rensselaer Polytechnic Institute, 459-72

Sahami M. (2012). Transformation of the school is necessary for the educational system. Higher Education Council. Retrieved October 20, 2013.

Sharifi H, Zhang Z. (1999). "A Methodology for Achieving Agility in Manufacturing Organisations: An Introduction," International Journal of Production Economics (62:1-2), ppC.T: 7-22.

Sherehiy B, Karwowski W, Layer J K. (2007). A Review of Enterprise Agility: Concepts, Frameworks and Attributes

Stewart, G. and Brown,K. (2009), "Human Resource Management: Linking Strategy to Practice, Hoboken, NJ: John Wisley \& sons, Inc. p 613

Sumukadas N, Sawhney R. (2014), “Workforce agility through employee involvement.”, IIE Transaction's, 31, $1111-1121$.

Torng Lin C, et al. (2005). Agility evaluation using fuzzy logic. Int. J. Production Economics. pp. 1-16

Tseng Y-H, Lin C-T. (2011),” Information Sciences, doi: 1101111 j. ins .21110140134.

Zhu Y. (2004).” Responding to the challenges of globalization: Hamman resource development in Japan”. Journal of world Business, 39 (4): 337-384. 